\title{
Construction of a Morphing Wing Rib Actuated by a NiTi Wire
}

\author{
Thais Campos de Almeida1, Osmar de Sousa Santos ${ }^{1}$, Jorge Otubo
}

\begin{abstract}
The main goal of this paper is to analyze if it is feasible to employ a trained shape memory alloy wire as a linear actuator to modify the camber of a morphing wing rib. In order to achieve this purpose, a morphing rib with a compliant trailing edge was proposed, developed, and subjected to structural analyses to ensure its flexibility. After the rib configuration was set, it was manufactured by a 3-D printer. The NiTi wire used as actuator was trained by a thermomechanical procedure based on a cycling process with a constant load application to present the two-way shape memory effect. In that way, the wire presents a determined length at its low-temperature phase and a shorter one at its high-temperature phase. Since the wire contraction and the torque applied by it are two crucial factors to define the camber curvature, it was decided to study two different wire lengths: 103.5 and $152.1 \mathrm{~mm}$. The aerodynamic performance of the morphing cambered airfoils was studied using XFOIL software and compared to that of conventional airfoils with single hinged flap. The results show that both morphing airfoils present better aerodynamic performance for small angles of attack.
\end{abstract}

KEYWORDS: NiTi, Morphing airfoil, Compliant mechanisms, Shape memory alloy actuator, Two-way shape memory effect.

\section{INTRODUCTION}

In aeronautics, "shape morphing" has been used to identify those aircraft that undergo certain geometrical changes to enhance or adapt to their mission profiles (Sofla et al.2010). There is not an exact definition of this kind of structures; however, there is a general agreement that the conventional hinged control surfaces or high lift devices, such as flaps or slats that provide discrete geometry changes, cannot be considered as "morphing" (Sofla et al. 2010). Therefore, it can be concluded that a smooth modification in the geometry, when it is required, certainly characterizes a morphing structure. Morphing aircraft structures can significantly enhance air vehicle performance (Kota et al. 2003); for example, a conventional hinged mechanism will create discontinuities over the wing surface leading to earlier airflow separation and drag increase (Shili et al. 2008). A wing with variable camber would provide an increase in aerodynamic efficiency (lift-to-drag ratio) resulting in reduction of fuel consumption and structural weight (Campanile and Sachau 2000). Due to these benefits, researches to design a morphing wing capable of changing the airfoil camber continuously is the most investigated approach of this technique (Sofla et al. 2010).

Parallel to this, it is a well known fact that one of the most concerns in aeronautical industry is the reduction of costs that can be achieved by several different ways including reducing drag, weight, fuel consumption, and maintenance. As already stated, a morphing structure has the ability to reduce the drag and, if combined with a light in weight and reliable actuator, may reduce the total weight and, consequently, fuel consumption as well as the need for maintenance. Knowing this fact, the Boeing Company has been actively developing a robust solid state active hinge pin actuator (AHPA) using shape memory alloy (SMA)

\footnotetext{
三 1.Instituto Tecnológico de Aeronáutica - Departamento de Materiais e Processos - Divisão de Engenharia Mecânica - São José dos Campos/SP - Brazil. Author for correspondence: Thais Campos de Almeida | Instituto Tecnológico de Aeronáutica - Departamento de Materiais e Processos - Divisão de Engenharia Mecânica | Praça Mal. Eduardo Gomes, 50 - Vila das Acácias | CEP: 12.228-900 - Sao José dos Campos/SP - Brazil | Email: thaistca@ita.br Received: 08/17/2015 | Accepted: 11/10/2015
} 
that can reliably apply high torque and angular displacement with a low space, weight and power burden. They compared the SMA actuator designed with equivalent actuators, such as a servo motor (torque of $66 \mathrm{in} \times \mathrm{lbs}$ and weight of $25 \mathrm{lbs}$ ), as well as a reduction gear (torque of $190 \mathrm{in} \times \mathrm{lbs}$ and weight of $16 \mathrm{lbs}$ ), and found that AHPA can provide comparable torque $(150 \mathrm{in} \times \mathrm{lbs})$, saving considerable weight (1 lbs) (Mabe et al. 2008).

Therefore, since the both topics addressed are promising in aeronautical industry, it is essential to further explore them. Because of that, the main goal of this study was to verify the feasibility of developing a morphing rib actuated by SMA wires. Next sections bring a summary of researches about those concepts in order to provide a better understanding of this research.

\section{AIRFOIL WITH VARIABLE CAMBER USING COMPLIANT MECHANISMS}

A compliant mechanism is a class of mechanisms that relies on elastic deformation of its constituent elements to transmit motion and/or force (Kota et al. 2003). It is not only flexible to deform, but also has enough stiffness to withstand external loads (Shili et al. 2008). The primary advantages of compliant mechanisms are that fewer parts, fewer assembly process, and no lubrication are needed. The disadvantages include fatigue problems and the fact that some of the input energy is stored as elastic work in the mechanism, thereby reducing efficiency (Luo et al.2005). Although there are disadvantages, the advantages of a compliant wing may overcome them depending on the compliant mechanism designed and, as it can be seen in the next examples, there are several different configurations already developed.

In 1999, Saggere and Kota designed a procedure for shape control that was extended to shape changes at the leading and trailing edges of an airfoil. The method was able to design compliant mechanisms similar to cobwebs making the least square errors between the shape-changed curve and the target curve as the objective function for optimization. The compliant mechanisms effect the desired shape changes in the airfoil by transforming the input torque (or rotation) into controlled displacements of a finite number of discrete points on the airfoil contour. The input actuator could be any torquegenerating source (with adequate power for the task) such as a conventional electrical servomotor or a smart material-based torque tube (Saggere and Kota 1999).

In 2000, Campanile and Sachau studied a structure called belt-rib, which would replace the classical rib. The belt-rib structural frame consists in a closed shell (belt) reinforced by in-plane stiffeners (spokes) (Campanile and Sachau 2000). The spokes were connected to the belt by flexible hinges which provided rotational freedom at the joints. The shape behavior of a belt-rib is defined by the configuration of the spokes and the bending flexibility of the belt. Campanile and Sachau also thought about the type of actuation that a belt-rib could receive. For example, if the actuator elements were SMA wires, a truss configuration could be adopted in order to provide a range of deformation downwards and upwards.

Another work in which Kota was involved, this time, in partnership with Hetrick (Kota et al. 2003), was a compliant trailing edge that could change from $0^{\circ}$ to $+15^{\circ}$ based on the deformation of beams connecting upper and lower surfaces. This study resulted in a patent (Kota and Hetrick 2006).

Shili et al. (2008) developed a systematic approach to design compliant structures to carry out required shape changes under distributed pressure loads. The method uses MATLAB and ANSYS to optimize the distributed compliant mechanisms by way of the ground approach and genetic algorithm (GA) to remove the elements possessive of very low stresses. The resultant structure could make its shape change from $0^{\circ}$ to $+9.3^{\circ}$ (Shili et al. 2008).

Based on the research of Kota and Hetrick, Medeiros (2011) designed, constructed and tested in a wind tunnel a wing composed of ribs with a compliant trailing edge. The trailing edge was made using a 3-D printer which used ABS as raw material.

Although made by two different authors, the ribs presented by Campanile and Hetrick have an aspect in common: the presence of inclined beams connecting upper and lower surfaces. Furthermore, the study of Medeiros showed that this solution provides favorable results and could be a promising concept for a morphing wing. Because of that, the rib configuration designed in this study was firstly based on the trailing edge already built by Medeiros (2011).

\section{SHAPE MEMORY ALLOY ACTUATION}

Smart materials refer to a class of materials that are able to respond dynamically to selected external stimulus (Dasgupta 2013). The materials themselves are not "smart" in the sense that they passively react to an input rather than making decisions or adapting themselves to the environment (Donadon and Iannucci 2014). Some examples include piezoelectric materials, shape memory materials (alloys and polymers) and electroactive polymers. 
SMAs are a type of smart materials that are characterized by the shape memory effect (SME). The SME is a unique property of certain alloys exhibiting martensitic transformations (Otsuka and Wayman 1998). Even though the alloy is deformed in the low-temperature phase, it recovers its original shape by the reverse transformation upon heating to a critical temperature called the reverse transformation temperature (Otsuka and Wayman 1998). The low-temperature phase, martensite, is a simple monoclinic arrangement of 24 variants, depending on the local stress field, and can appear as twinned or detwinned (Ko et al. 2014), whereas the high-temperature phase, austenite, consists of a body-centered cubic structure. When a SMA is heated, it begins to transform from martensite into austenite phase in a process called martensitic transformation. The austenite start temperature $\left(A_{s}\right)$ is the temperature in which this transformation starts, and the austenite finish temperature $\left(\mathrm{A}_{\mathrm{f}}\right)$ is the temperature in which this transformation is complete. Once a SMA is heated beyond $A_{s}$, it begins to contract and transform into the austenite structure, i.e. to recover in its original form. During the cooling process, the transformation starts to revert to the martensite phase at the martensite start temperature $\left(M_{s}\right)$ and is complete when it reaches the martensite finish temperature $\left(M_{f}\right)$ (Jani et al. 2014).

The two-way shape memory effect (TWSME) is a property that a SMA can acquire after certain thermomechanical training. In this effect, the alloy can remember its shapes in both high and low temperature without the need of an external stress to impose its low temperature format.

SMA has already been used in aeronautical industry as actuator in an active serrated aerodynamic device known as a variable geometry chevron (VGC) capable of reducing noise during take-off (Jani et al. 2014). Indeed, the use of SMA as actuator is promising, since it would eliminate the need for hydraulics and electrical motors (Mabe et al. 2008). An actuator can be reduced to a single SMA wire providing simplicity, compactness, and safety (Dasgupta 2013). Furthermore, the stroke and force required for a particular actuator can be easily achieved by using the right SMA (Dasgupta 2013), since SMA properties can have a wide variation according to the chemical compositions and heat treatments to which the alloy has been subjected (Barbarino et al. 2014). There are three major types of SMA systems at present, namely Cu-based (mainly CuAlNi and $\mathrm{CuZnAl}$ ), NiTi-based, and Fe-based (e.g. FeMnSi, FeNiC, and FeNiCoTi) (Barbarino et al. 2014). NiTi-based shape memory alloys have, to date, provided the best combination of properties for most commercial applications (Dasgupta 2013). Moreover, it has two great advantages: high actuation stress (up to 500 $\mathrm{MPa}$ ) (Sun et al. 2012) and large recoverable strain (about 8\%) (Barbarino et al. 2014). Due to their benefits, there are some studies about the use of SMAs in aeronautical industry, more specifically, as an actuator capable of changing the camber of an airfoil, producing a morphing wing, as it can be seen in the next two examples.

Strelec et al. (2003) used two-way SMA wires as linear actuators attached to certain points inside a shell, whose geometry was an airfoil, made of ABS. When heated, the SMA wires contracted, cambering the airfoil and, when they had been cooled, the airfoil returned to its previous shape. Experimental results proved that there was a trailing edge deflection of $6.0 \mathrm{~mm}$ (Strelec et al. 2003).

Ko et al. (2014) constructed a wing with a morphing flap using SMA spring as actuator. Unlike from a compliant trailing edge, in their study, the airfoil camber is modified by means of multiple elements joined together in a way that allowed relative rotations of adjacent elements causing a smooth contour. Results show that a gain of $72 \%$ in lift-to-drag ratio can be achieved when compared with a conventional hinged flap.

Although there are several shapes that a SMA can acquire in order to be used as actuator, such as torque tubes, strips, and springs, in this work, it was chosen to use a trained NiTi wire working as a linear actuator due to its simplicity and space saving.

\section{METHODOLOGY RIB CONFIGURATION}

\section{Relevant Factors}

In order to better understand the project, it is crucial to know the steps that lead the study. The first step is to propose a wing rib configuration using the Computer Aided Design (CAD) software CATIA. The configuration was firstly based on the trailing edge already built by Medeiros (2011). The second step consists in analyzing the rib shape by two primary parameters: structural and aerodynamic. The structural analysis is performed using the software based on finite element method (FEM) CATIA, since the configuration was already built using it; for simplicity, it was used for this other purpose once more. The structural analysis is a very important step since it will provide information about the structure flexibility which is a critical requirement in this project: if the structure is not flexible enough, the SMA wire could not afford the necessary strength 
to camber it. The aerodynamic analysis is equally important, once it will inform if there was an improvement in the quality of the air flow around the airfoil.

Another analysis that should be performed concerns the position of the SMA actuator, since the wire length will be responsible for the presence or absence of camber. While in martensitic state, the wire will be in its longest length: the rib will not be cambered. When heated, the wire will shrink (austenitic state), cambering the airfoil. The resulted camber, certainly, will depend on the amount of the wire contraction. Figure 1 schematically shows such effect (the blue line represents the SMA wire while the circles represent the positions where the wire extremities will be fastened to the rib).

After the configuration is set, the rib will be manufactured using a 3-D printer.

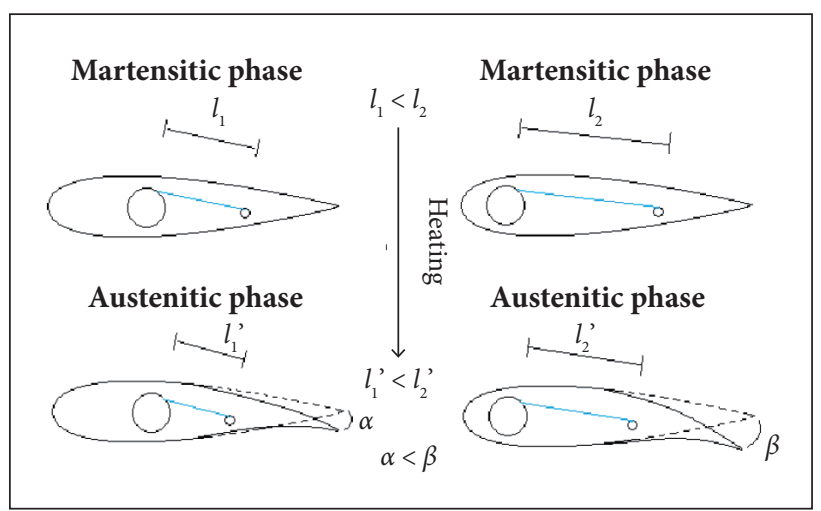

Figure 1. Schema showing the effect of the wire length (blue) in airfoil camber. $I_{1}$ and $I_{2}$ refer to the wire length.

\section{Design Process}

The rib final configuration is presented in Fig. 2. The airfoil used was the NACA0012 because it is simpler to build and it is symmetric (it has no camber): the lift produced when in zero angle of attack is null. It has trusses near the leading edge to provide rigidity to this region. The spar (an aluminum tube) is attached to the second hole $(A)$, while the third hole was made for saving material. The fourth hole $(B)$ has a smaller diameter in order to be attached to a light in weight aluminum tube that will work as stringer.

In the first configuration, the flexible trailing edge length (L) covered $35 \%$ of the total chord, also the first beam had a slope $(\beta)$ of $33.7^{\circ}$. The SMA wire would be fasten to $A$ and $B$ tubes. The idea is to provide the highest possible torque and wire length, thus the wire should be attached to the positions indicated by the red dots in Fig. 2 .
For the subsequent structural analyses, it was created a 3-D mesh using octree tetrahedron elements of linear type, with $1 \mathrm{~mm}$ size and $0.3 \mathrm{~mm}$ absolute sag. The rib will be manufactured by a 3-D printer that uses poly-lactic acid (PLA) as raw material. Table 1 shows the mechanical properties of PLA (Mathew et al. 2005) employed to perform the structural analyses.

It is important to note that, at this point, it was not known the quantity of load that the NiTi wire would be capable of affording or its percentage of contraction. To observe the flexibility of the structure, a load of $5 \mathrm{~N}$ (randomly chosen value) was applied in point $\mathrm{B}$ directed to point $\mathrm{A}$. This structural analysis showed that this first design was rigid: the trailing edge deflected only $2.77 \mathrm{~mm}\left(1.8^{\circ}\right)$.

Due to this fact, $L$ was expanded to $50 \%$ of the total chord length, creating the second configuration. Its structural analysis proved that this rib is more flexible: the trailing edge deflected $5.5 \mathrm{~mm}\left(2.5^{\circ}\right)$. Moreover, both configurations showed that there is a maximum stress concentration located at the upper region of the first beam. This fact was already studied in the Medeiros' work (2011). The maximum stress of the first configuration was $14.5 \mathrm{MPa}$ while for the second one it was $11.6 \mathrm{MPa}$, an improvement of $20 \%$. This fact induced a study about the first beam slope. It was constructed a third design with $\beta$ equal to $45.6^{\circ}$. A fourth configuration with a greater inclination $\left(\beta<33.7^{\circ}\right)$ would decrease the rigidity of the rib, so this idea was discarded.

The structural analysis of the third configuration showed that the maximum stress was $14.8 \mathrm{MPa}$ and located at the same point. Therefore, there was a worsening of $27.6 \%$ when compared with the second configuration. Furthermore, the third configuration, when loaded by $10 \mathrm{~N}$, presented an abrupt change of curvature at lower surface around the first beam (Fig. 3b), which may cause a detachment of the air flow. Because

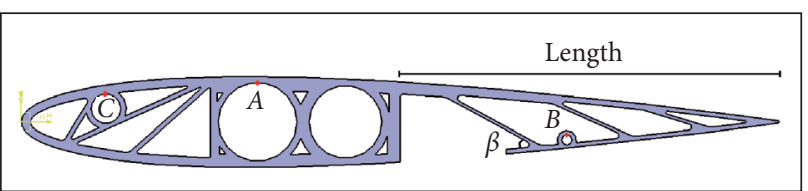

Figure 2. Final configuration.

Table 1. Mechanical properties of PLA.

\begin{tabular}{|l|c|}
\hline Young's modulus & $3.6 \mathrm{GPa}$ \\
\hline Poisson ratio & 0.36 \\
\hline Density & $12,600 \mathrm{~kg} / \mathrm{m}^{3}$ \\
\hline Yield strength & $49.6 \mathrm{MPa}$ \\
\hline
\end{tabular}


of these facts, it was decided to maintain the studies using the second configuration.

Another interesting investigation concerns the position of the tubes $A$ and $B$ since it will affect the trailing edge deflection. On the one hand, it is better to maintain point $B$ far from the trailing edge in order to be also far from the chord line providing a greater torque. On the other hand, it is a good idea to change point $A$ towards a position nearer the leading edge because it would enlarge total distance between these points, increasing wire size. Thus, it was created a new position corresponding to point $C$ in Fig. 2.

It is important to note that the position of tube/point $A$ or $C$ could be modified to achieve a wire length/torque sufficient to produce a required camber, or, more specifically, a required lift and drag. In other words, $A, B$, and $C$ positions could be rearranged in order to the wing be able to adapt to different flying conditions. In this study, both configurations will be studied: the one produced by a wire size of $\mathrm{A}-\mathrm{B}$ and the other by a wire size of $\mathrm{C}-\mathrm{B}$.

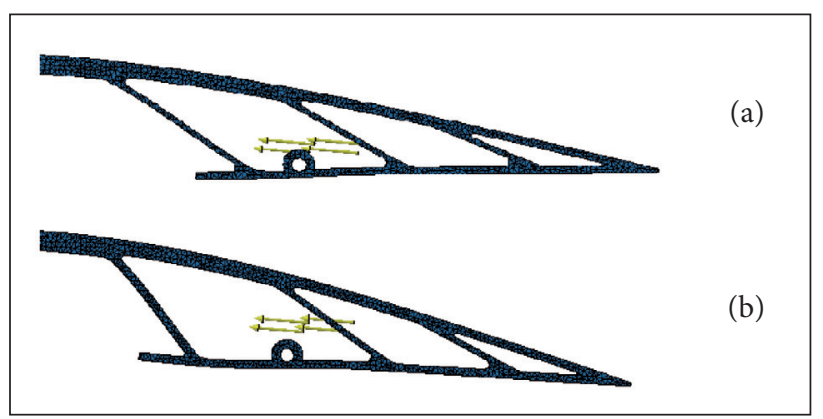

Figure 3. Trailing edge detail for a structural analysis with a load of $10 \mathrm{~N}$ for: (a) Second and (b) Third configurations.

\section{WIRE MANUFACTURING PROCESS}

The starting material was a NiTi ingot melted by vacuum induction melting (VIM) with controlled chemical composition. The ingot was hot-formed and then wire drawn to a wire diameter of $0.4 \mathrm{~mm}$ at the ITASMART facilities.

\section{TENSILE TEST}

The mechanical properties of the NiTi alloy manufactured were investigated by an Instron 5500R tensile testing machine. The specimen tested was a wire with a diameter of $2.058 \mathrm{~mm}$. The test was performed using a strain rate of $2 \mathrm{~m} / \mathrm{min}$ and a load cell of $30 \mathrm{kN}$ until the specimen rupture.

The behavior of a twinned martensitic NiTi SMA under tension follows four basic steps: (I) at the beginning of deformation, it occurs a monotonic increase in the stress with increasing strain amplitude until about $1 \%$ strain due to the elastic accommodation of martensite twins; (II) the reorientation of martensite variants causes a slight stress-drop followed by a stress-plateau until about $6 \%$ strain; (III) the elastic deformation of fully reoriented martensite causes a further increase in the stress with the increasing deformation; and (IV) a final plastic deformation of the reoriented martensite with further deformation leads to rupture (Liu et al. 1998).

\section{NiTi WIRE TRAINING}

The wire was trained in order to acquire the TWSME. There are several methods of training for TWSME. In this study, it was chosen an already known process based on constant load application. This method has four steps, as following:

1. The wire is attached to a platform in a room where the temperature is below $M_{f}$

2. The wire is deformed (extended) by a tensile load equal to the stress-plateau.

3. The wire is heated for $20 \mathrm{~s}$ by Joule effect until it achieves a temperature above $A_{f}$ in order to recover its length.

4. The power is switched off, and the wire is cooled down to room temperature (below $M_{f}$ ) by natural convection, being deformed by the load again.

The thermal cycle, composed of steps 3 and 4, is repeated several times until it reaches stable results. According to Hebda and White (1995), after 2,000 cycles, Ni-55at\%.Ti SMA wires achieved the stabilization of TWSME behavior. To ensure the TWSME behavior, the thermal cycle was repeated about 4,600 times. Figure 4 shows a scheme enlightening the training procedure (steps 3 and 4).

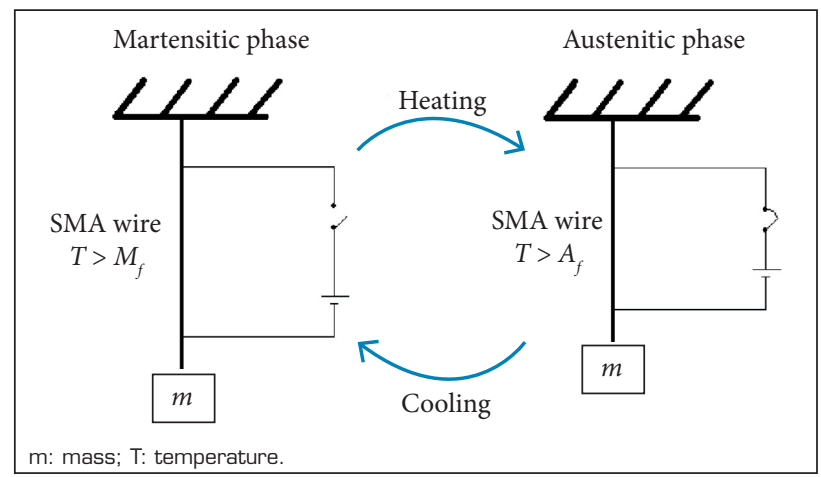

Figure 4. Scheme showing the thermal cycle responsible for inducing the TWSME behavior.

\section{CONNECTION BETWEEN RIB AND SMA WIRE}

It was constructed a device to observe the camber produced by each wire configuration. In this device, the rib is positioned close to a millimeter paper to assist the 
visualization of the new airfoil after actuation, as it can be seen in Fig. 5. The airfoil chord is $250 \mathrm{~mm}$, which results in a wire size $A-B$ of $103.5 \mathrm{~mm}$ (Fig. 5a) or $C-B$ of $152.1 \mathrm{~mm}$ (Fig. 5b). The wires were cut and then connected to the tubes by screw and washers.

The electrical current flows through tubes $A$ and $B(A B$ configuration) or $C$ and $B$ ( $C B$ configuration), heating the SMA wire by Joule effect.

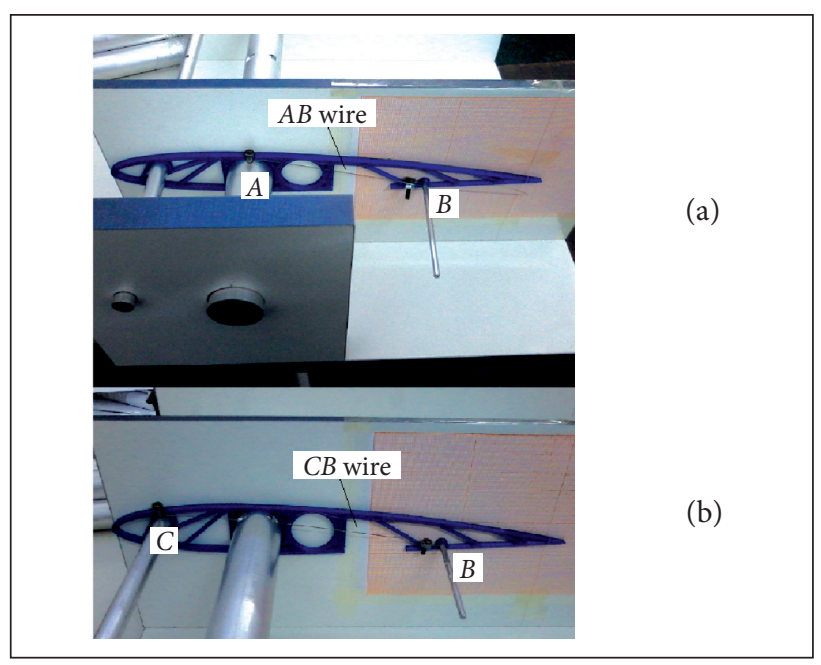

Figure 5. Rib attached to the constructed device along with (a) $A B$ and (b) $C B$ wires.

\section{AERODYNAMIC ANALYSIS}

After heating the SMA wire, the rib will camber, creating a new airfoil. The points of the upper and lower surfaces of this generated airfoil are detected by drawing the contours in the millimeter paper (Fig. 5). Then, the aerodynamic characteristics of these new airfoils are studied using the XFOIL software. The analysis performed was viscous with Reynolds number equal to 300,000 , which is included in the range of large model airplanes (Lissaman 1983). The angle of attack varied from $-10^{\circ}$ to $14.5^{\circ}$ at $0.5^{\circ}$ intervals. The results will be analyzed by two primary factors employed to judge the quality of an airfoil (Anderson 1991), as follows:

- The lift-to-drag ratio $\left(L / D\right.$ or $\left.c_{l} / c_{d}\right)$ since an efficient airfoil produces lift with a minimum of drag. An increased lift-to-drag ratio promises a longer operation distance and elongated flight time with the same amount of fuel under the same flight conditions (Ko et al. 2014).

- The maximum lift coefficient $\left(c_{l, \max }\right)$, which determines the stalling speed of an airfoil. Increasing it, it will obtain lower stalling speeds or higher payload weights at the same speed (Anderson 1991).
Furthermore, the aerodynamic characteristics of the morphing airfoil will be compared with the conventional hinged-flap NACA0012 airfoil deflected by the same amount of the morphing rib trailing edge.

\section{AEROELASTIC ANALYSIS}

Due to the rib flexibility, the trailing edge deflection caused by the wire contraction may experience a reduction when subjected to aerodynamic loading. The real deflection may be calculated by performing the sum of moments at the articulation point, which results in Eq. 1:

$$
\tau_{\text {Wire }}=\tau_{\text {Structure }}+H
$$

where:

$H$ is the aerodynamic moment of the flexible surface; $\tau_{\text {Wire }}$ is the torque applied by the wire; $\tau_{\text {Structure }}$ is the torque resisted by the structure.

The aerodynamic moment at the articulation point is calculated by Eq. 2 :

$$
\frac{H}{\text { span }}=q C_{h} C_{f}^{2}
$$

where:

$q$ is the dynamic pressure; $c_{f}$ is the flap chord; $C_{h}$ is the articulation coefficient moment.

The articulation coefficient moment can be estimated by using the function fmom inside de oper menu in XFOIL. However, as it can be observed from Eq. 2, $H$ is a function of the wingspan, which is not known yet. Moreover, it also depends on the angle of attack. Just for the sake of curiosity, it will be studied the case for an angle of attack null and a wing span of $0.455 \mathrm{~m}$. The other parameters employed are displayed in Table 2.

Table 2. Parameters used for the calculation of the articulation moment.

\begin{tabular}{l|c} 
Reynolds number [Re] & 300,000 \\
\hline Mach (M) & 0.051 \\
\hline Velocity $[$ C & $17.46 \mathrm{~m} / \mathrm{s}$ \\
\hline Air density $[\rho]$ & $1.23 \mathrm{~kg} / \mathrm{m}^{3}$ \\
\hline $\mathrm{C}_{\mathrm{f}}$ & $0.125 \mathrm{~m}$
\end{tabular}

For small to moderate angles, it may be considered that the articulation moment is a linear function of control surface deflection $(\delta)$ and the angle of attack (Wright and Cooper 2007); 
since the last one will be considered null, this relation may be represented by Eq. 3:

$$
C_{h}=C_{h(\delta)} \delta
$$

Therefore, $H$ may be represented by Eq. 4 :

$$
H=\left(q s c_{f}^{2} C_{h(\delta)}\right) \delta
$$

where:

$s$ means span.

$\tau_{\text {Structure }}$ may be estimated using CATIA. Since the rib trailing edge rotates around the articulation point, it may be supposed that the rib flexible region is equivalent to a torsion spring, as shown in Fig. 6.

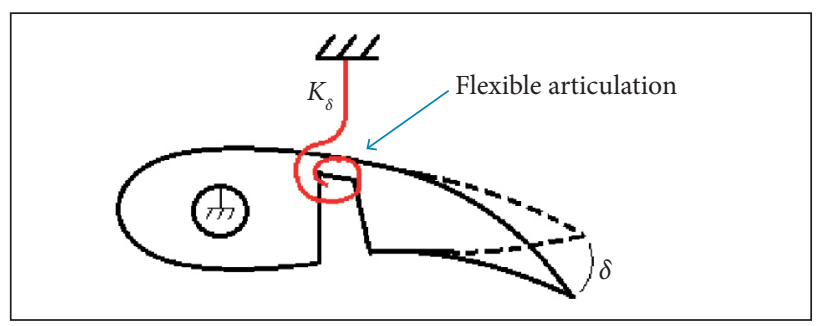

Figure 6. Schema showing the equivalence between the flexible articulation and the torsion spring, where $K_{\otimes}$ is the articulation stiffness.

Thus, the articulation torque applied by the trailing edge structure can be calculated using Eq. 5:

$$
\tau_{\text {Structure }}=K_{\delta} \delta
$$

The articulation stiffness $\left(K_{\delta}\right)$ may be found by the same approach as the one used in the structural analysis. Varying the value of the torque applied by the wire in CATIA, it will be extracted a curve showing the relation between $\tau_{\text {structure }}$, which is equal to $\tau_{\text {Wire }}-$ in this case, because $H$ is null -, and the trailing edge deflection. This relation must be linear with the slope equal to $K_{\delta}$ as stated in Eq. 5 .

Finally, considering that the torque applied by the wire is constant and depends exclusively on its temperature, it can be estimated by using the relation found previously for a null $H$. In this way, the real deflection may be calculated by Eq. 6:

$$
\delta_{\text {Real }}=\frac{\tau_{\text {Wire }}}{q s c_{f}^{2} C_{h(\delta)}+K_{\delta}}
$$

\section{RESULTS}

\section{WIRE MANUFACTURING PROCESS}

Table 3 shows the chemical composition of the NiTi wire in at $\%$.

Table 4 presents the martensite transformation temperatures (MTT) of the NiTi alloy. They were measured using a differential scanning calorimetry equipment (DSC404C Pegasus - NETZSCH) located at the ITASMART facilities. As it can be noted, every characteristic temperature is above room temperature, i.e. the alloy is in the martensite phase in room temperature.

Table 3. NiTi alloy chemical composition.

\begin{tabular}{|c|c|c|c|}
\hline Ni [at\%.] & Ti [at\%.] & C [at\%.] & O [at\%.] \\
\hline 49.420 & 50.409 & 0.060 & 0.111 \\
\hline
\end{tabular}

Table 4. Martensitic transformation temperatures.

\begin{tabular}{|c|c|c|c|}
\hline$M_{s}\left({ }^{\circ} \mathrm{C}\right)$ & $M_{f}\left({ }^{\circ} \mathrm{C}\right)$ & $A_{s}\left({ }^{\circ} \mathrm{C}\right)$ & $A_{f}\left({ }^{\circ} \mathrm{C}\right)$ \\
\hline 53.2 & 43.1 & 69.3 & 84.6 \\
\hline
\end{tabular}

\section{TENSILE TEST}

The stress-strain curve of the NiTi wire is exhibited in Fig. 7, and, as it can be noted, it presents the characteristic behavior of a twinned martensitic NiTi SMA under tension.

The stress-plateau (region II) of this wire is about $136 \mathrm{MPa}$. Therefore, the strength to which the wire should be subjected in its training is, approximately, $17 \mathrm{~N}$, corresponding to a mass of $1.74 \mathrm{~kg}$. However, as the cycles are reproduced, more defects are introduced in the wire, which generates a new state after each cycle and changes the stress-plateau to a lower level, modifying the strength required for the training. This is noted due to the change in the wire diameter size and length. As more cycles were reproduced, the wire became thinner and longer. The solution found to solve this problem was to apply less strength

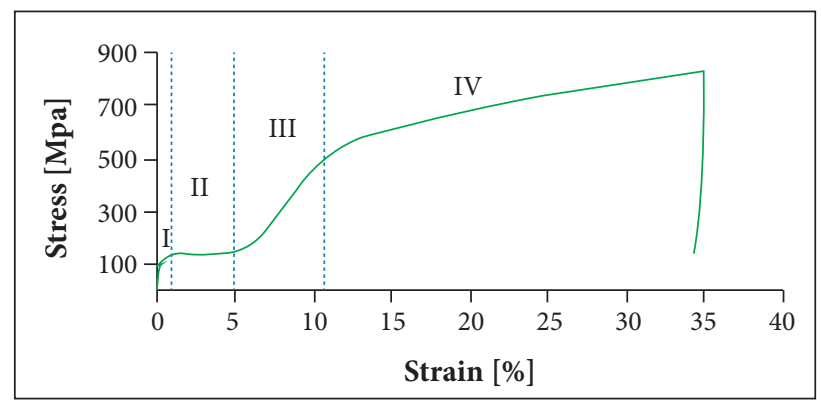

Figure 7. True strain-stress curve of the NiTi alloy. 
at each cycle until the wire achieve a stable diameter size, which occurred at a load of $1.32 \mathrm{~kg}$.

\section{TRAILING EDGE DEFLECTION}

The trailing edge (TE) deflection due to each wire size studied is reported in Table 5. The TE deflection can be seen in Fig. 8, where six situations are presented: TE before (a); during (b), and after actuation (c) for (1) $A B$ wire configuration or (2) $C B$ wire configuration. It is important to note that, after the actuation, the rib returned its shape to the original one, without the visible presence of permanent deformations.

The morphing cambered airfoils are displayed in Fig. 9. It can be noted that, although there is a great difference between the lengths of the studied wires (about 50\%), there is not a great difference between the resulted airfoils. This occurs because $A B$ wire provides more torque since point $A$ is farther from symmetry line - chord line - $(13 \mathrm{~mm})$ than point $C(9.266 \mathrm{~mm})$. Therefore, although wire size is crucial for the resulted TE deflection, the torque applied also plays a fundamental role.

\section{AERODYNAMIC ANALYSIS}

The morphing airfoils and their respective hinged-flaps NACA0012 are exhibited in Figs. 10 and 11. The hinged-flap coordinates were located in order to better reproduce the

Table 5. Results for both configurations studied.

\begin{tabular}{|c|c|c|}
\hline \multirow{2}{*}{} & \multicolumn{2}{|c|}{ Wire } \\
\cline { 2 - 3 } & $A B$ & $C B$ \\
\hline Length before heating $(\mathrm{mm})$ & 103.5 & 152.1 \\
\hline Length after heating $(\mathrm{mm})$ & 102.4 & 150.5 \\
\hline Percentage of contraction & 1.06 & 1.05 \\
\hline TE deflection $(\mathrm{mm})$ & 11.6 & 14.0 \\
\hline TE deflection $\left({ }^{\circ}\right)$ & 5.3 & 6.4 \\
\hline
\end{tabular}

morphing airfoil: $x$ is equal to $50 \%$ of the chord and $y$ is attached to the upper surface. It is important to note that, in the cases studied, there are not great differences between the morphing or flapped configurations. However, these small differences can have a large impact on aerodynamic coefficients.

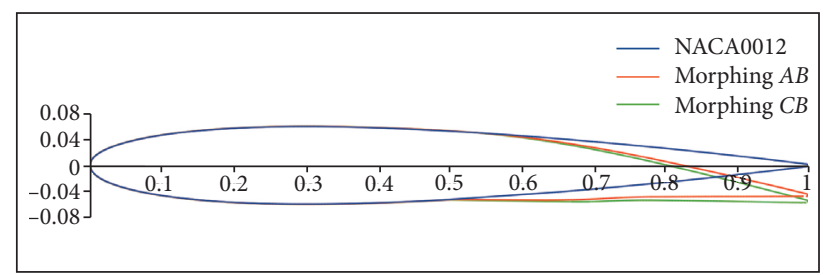

Figure 9. Morphing airfoils derived from NACA0012 after actuation of $A B$ or $C B$ wire.

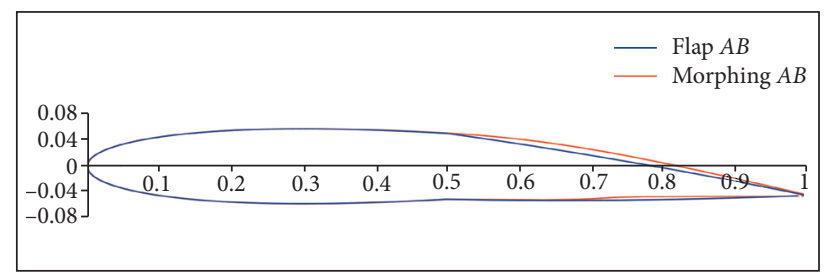

Figure 10. $A B$ morphing (actuated by $A B$ wire) and hinged-flap airfoils with the same TE deflection.

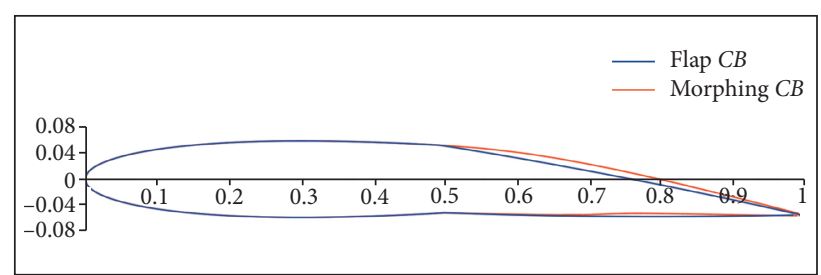

Figure 11. $C B$ morphing (actuated by $C B$ wire) and hinged-flap airfoils with the same TE deflection.

\section{Results for AB Morphing Airfoil}

According to the aerodynamic results shown in Fig. 12 (subgroup I), the $A B$ morphing airfoil presents better performance - larger lift associated with less drag - than the $A B$ hinged-flap airfoil mostly for small angles of attack.

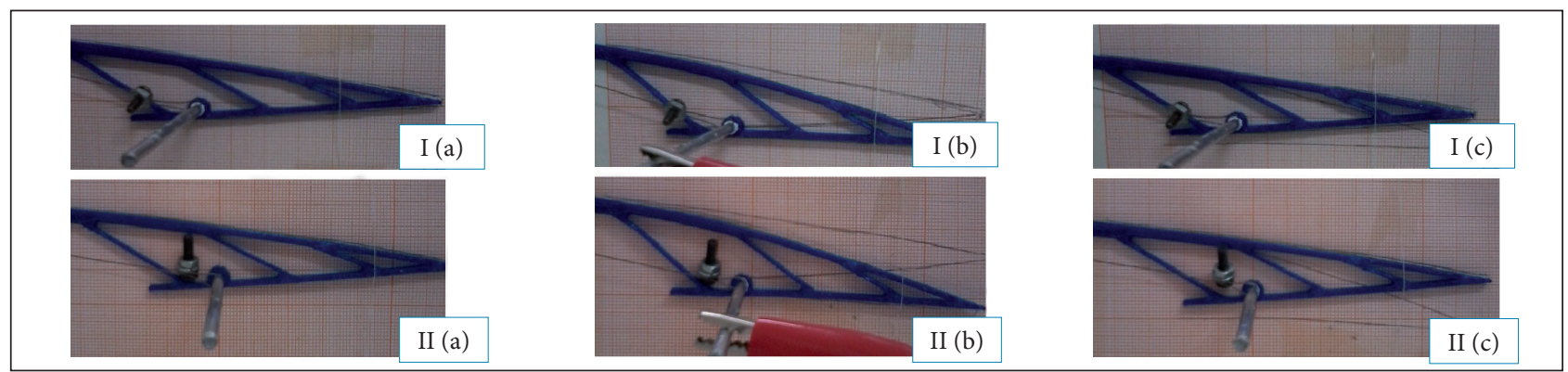

Figure 8. Trailing edge: Before (a), During (b), and After heating (c) for $A B$ (I) or $C B$ (II) wire. 
In Fig. 12a, it can be noted that, with the cambering of the airfoil either by the morphing structure or by deflecting the flap, the maximum lift coefficient $\left(c_{l, \text { max }}\right)$ increases while the critical angle of attack $\left(\alpha_{\text {stall }}\right)$ decreases. This property reflects the aerodynamic characteristics of the presence of high-lift devices, since as the flap deflects downward, the lift curve simply translates to the left because the angle of attack that generates a null lift $\left(\alpha_{\mathrm{L}=0}\right)$ becomes more negative as the camber increase (Anderson 1991). Moreover, the $c_{l, \max }$ produced by the morphing airfoil $\left(c_{l, \max }=1.3536\right)$, in the studied conditions, is slightly greater (about $2 \%$ ) than the one produced by the hinged-flap airfoil $\left(c_{l, \max }=1.3265\right)$. The morphing airfoil has a maximum lift-to-drag ratio of 86.97 at an angle of attack equal to $1.5^{\circ}$, while for the flapped airfoil it is 78.87 at $2^{\circ}$. Analyzing the condition of maximum lift-to-drag ratio for both airfoils, the morphing airfoil presents a $10.26 \%$ gain, with $0.14 \%$ increase in lift and $9.18 \%$ decrease in drag. Furthermore, the improvement in the efficiency of the morphing airfoil $\left(c_{l} / c_{d}\right)$ occurs until an angle of attack of $1.5^{\circ}$; after that, both airfoils present similar lift-to-drag ratios.

\section{Results for CB Morphing Airfoil}

In accordance with the previous airfoil, the $C B$ morphing presents better performance - larger lift associated with less drag - than the $C B$ hinged-flap airfoil mostly for small angles of attack (Fig. 12, subgroup II). Moreover, the $C B$ morphing presented a slightly greater $c_{l \text { max }}\left(c_{l \text { max }}=1.3874\right)$ than the flapped one

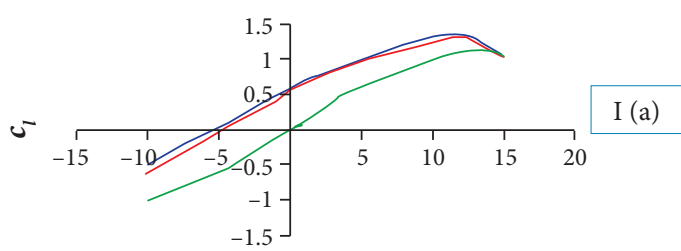

$\alpha\left[^{\circ}\right]$
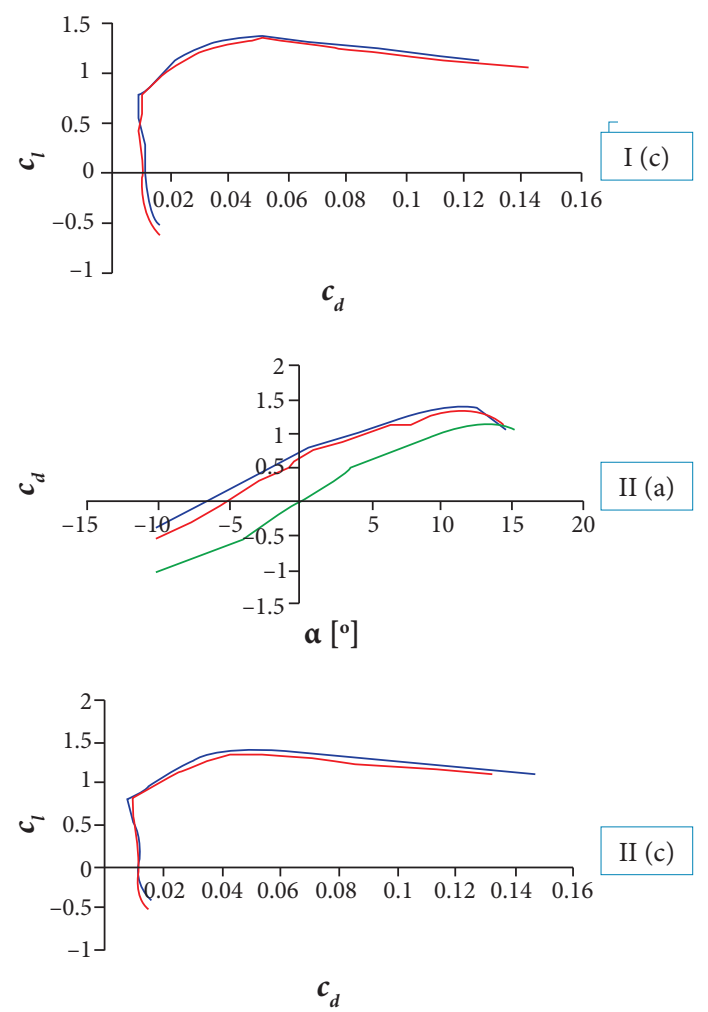

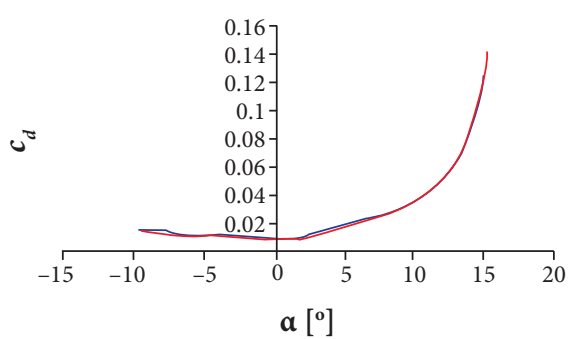

I (b)

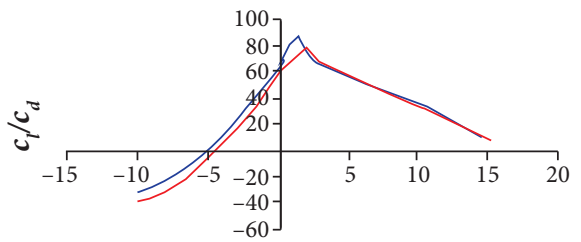

$\alpha\left[^{\circ}\right]$

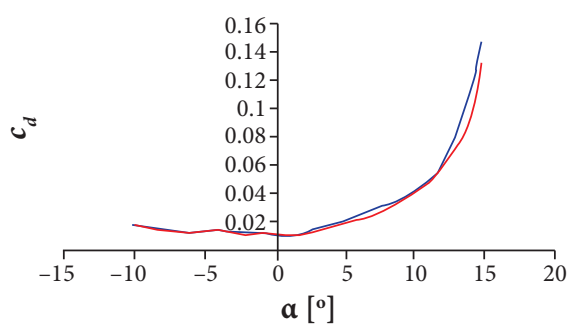

II (b)

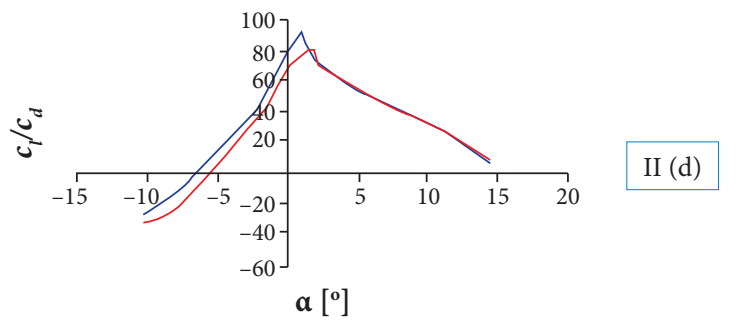

— NACA0012 - Morphing $A B$ or $C B$ - Flap $A B$ or $C B$

Figure 12. Aerodynamic coefficients for (I) $A B$ and (II) $C B$ morphing airfoil: (a) Lift coefficient versus angle of attack; (b) Drag coefficient versus angle of attack; (c) Drag polar curve; (d) Lift-to-drag ratio versus angle of attack. 
$\left(c_{l, \max }=1.3393\right)$, about $3.59 \%$ in gain. The $C B$ morphing airfoil has a maximum lift-to-drag ratio of 91.00 at an angle of attack of $1^{\circ}$, while, for the flapped airfoil, it is 80.34 at $1.5^{\circ}$, which indicates an improvement of $13.26 \%$ in maximum lift-to-drag ratio due to a $2.15 \%$ increase in lift and a $9.81 \%$ decrease in drag. For angles of attack less than $1.5^{\circ}$, the efficiency of the morphing airfoil is higher than that of the hinged-flap one; however, for angles greater than $1.5^{\circ}$, both have similar results.

\section{AEROELASTIC ANALYSIS}

In order to find the slopes of Eqs. 4 and 5, it was made a linear regression using the method of least squares of the extracted data. The results are represented by lines and the corresponding equation in Figs. 13 and 14.

Using the equations in Fig. 14, $\tau_{\text {Wire }}$ may be estimated by replacing $\delta$ with $5.3^{\circ}$ or $6.4^{\circ}$ depending on the wire configuration. Furthermore, using Eq. 6, we have the real deflection for each case. Table 6 shows the results.

\section{CONCLUSIONS}

Morphing airfoils is a very important topic in aeronautics since they can provide gains in efficiency translated into

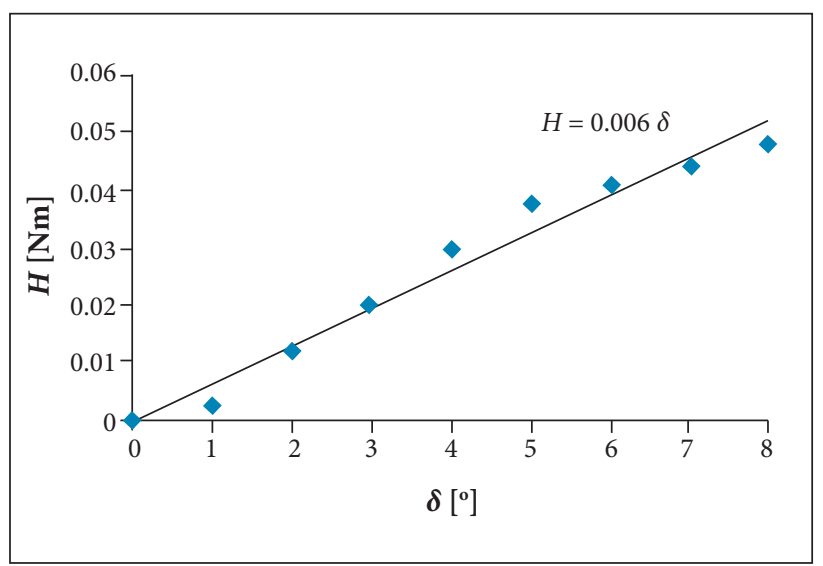

Figure 13. Linear regression showing the relationship between $H$ and $\delta$. longer operation distances and higher payload weights. Moreover, when associated with small, reliable, and lightweight actuator, the system becomes simpler, avoiding the need for electrical or hydraulic motors. Because of these benefits, in this work, it was designed a morphing airfoil with a compliant trailing edge actuated by a SMA wire responsible to deflect it.

The findings suggest that this solution is promising since both morphing airfoils presented better aerodynamic results when compared with the correspondent conventional single hinged-flap airfoil. The $A B$ wire actuation provided a trailing edge deflection of $5.3^{\circ}$ resulting in a gain of $10.26 \%$ in maximum lift-to-drag ratio and an increase of $2 \%$ in the maximum lift coefficient. The $C B$ wire actuation provided a more cambered airfoil, with a trailing edge deflection of $6.4^{\circ}$, corresponding to an improvement of $13.26 \%$ in maximum lift-to-drag ratio and a gain of $3.59 \%$ in the maximum lift coefficient. Nevertheless, for angles of attack above $1.5^{\circ}$,

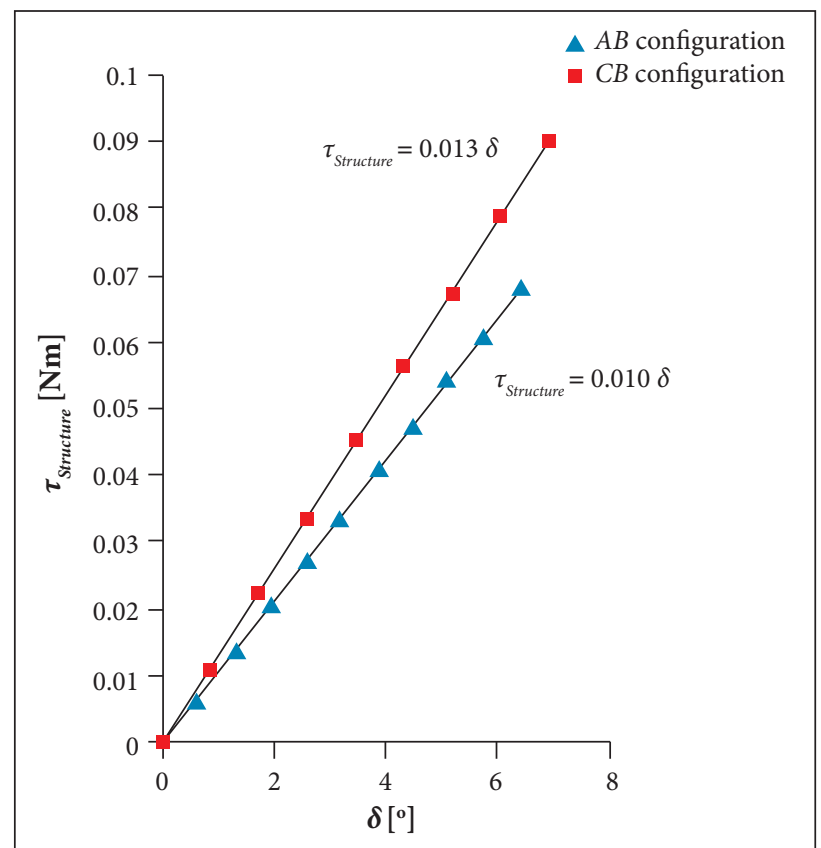

Figure 14. Linear regression showing the relationship between $\tau_{\text {Structure }}$ and $\delta$ for each wire configuration.

Table 6. Real trailing edge deflection for each wire configuration.

\begin{tabular}{|c|c|c|c|c|}
\hline Configuration & $\begin{array}{c}\text { Deflection without } \\
\text { aerodynamic loads }\end{array}$ & $\tau_{\text {Wire }}(\mathbf{N m})$ & $\begin{array}{c}\text { Real deflection } \\
\text { (with aerodynamic loads) }\end{array}$ & $\begin{array}{c}\text { Command } \\
\text { efficiency }\end{array}$ \\
\hline$A B$ & $5.3^{\circ}$ & 0.053 & $3.31^{\circ}$ & $62.5 \%$ \\
\hline$C B$ & $6.4^{\circ}$ & 0.083 & $4.38^{\circ}$ & $68.4 \%$ \\
\hline
\end{tabular}


the efficiency of both morphing airfoils is comparable to the hinged-flap one.

These aerodynamic results do not take into account the rib flexibility. Nevertheless, according to the aeroelastic analysis, under aerodynamic loading, the real trailing edge deflection would be less than that commanded by the SMA wire contraction. Therefore, although a morphing rib presents advantages, if applied in an actual airplane, the project must consider that its trailing edge deflection will experience a reduction.

\section{ACKNOWLEDGEMENTS}

The authors wish to thank FAPESP, CNPq Universal (476030/2011-0), CNPq/Casadinho/PROCAD (552199/2011-70) UFCG/UFRJ/ITA, PRO-INFRA (2012, 2013 and 2014), CAPES/ITA 005/2014 for fellowship for one of the authors. Thanks are due to Villares Metals S. A., Multialloy Metais Especiais Ltda, Marcenaria Exclusiva Mobile, Rafael Endlich Pimentel, Roberto Gil Annes da Silva and Odair D. Rigo for supporting the ITASMART (ITA Shape Memory Alloys Research and Technology Group).

\section{REFERENCES}

Anderson JD (1991) Fundamentals of Aerodynamics. New York: McGraw-Hill. Chapter 4, Incompressible flow over airfoils; p. 247-314.

Barbarino S, Flores EIS, Ajaj RM, Dayyani I, Friswell MI (2014) A review on shape memory alloys with applications to morphing aircraft. Smart Mater Struct 23(6): 1-19. doi: 10.1088/0964-1726/23/6/063001

Campanile LF, Sachau D (2000) The belt-rib concept: a structronic approach to variable camber. J Intell Mater Syst Struct 11(3):215-224. doi: 10.1106/6H4B-HBW3-VDJ8-NB8A

Dasgupta R (2013) Designing shape memory materials or the future. Metalworld 74-78.

Donadon MV, lannucci L (2014) A numerical study on smart material selection for flapped and twisted morphing wing configurations. J Aerosp Technol Manag 6(3):281-290. doi: 10.5028/jatm.v6i3.341

Hebda DA, White SR (1995) Effect of training conditions and extended thermal cycling on nitinol two-way shape memory behavior. Smart Mater Struct 4(4):298-304. doi: 10.1088/0964-1726/4/4/010

Jani JM, Leary M, Subic A, Gibson MA (2014) A review of shape memory alloy research, applications and opportunities. Mater Des 56:1078-1113. doi: 10.1016/j.matdes.2013.11.084

Ko SH, Bae JS, Rho JH (2014) Development of a morphing flap using shape memory alloy actuators: the aerodynamic characteristics of a morphing flap. Smart Mater Struct 23(7):074015. doi: 10.1088/0964-1726/23/7/074015

Kota S, Hetrick J, inventors; Flexys, INC, assignee. 2006 Aug 24 Adaptive compliant wing and rotor system. United States Patent US 20060186269 A1

Kota S, Hetrick J, Osborn R, Paul D, Pendleton E, Flick P, Tilmann C (2003) Design and application of compliant mechanisms for morphing aircraft structures. Proceedings of the SPIE 5054; San Diego, USA.

Lissaman PBS (1983) Low-Reynolds-number airfoils. Ann Rev Fluid Mechanics 15:223-239.doi: 10.1146/annurev. fl. 15.010183 .001255

Liu Y, Xie Z, Humbeeck JV, Delaey L (1998) Asymmetry of stressstrain curves under tension and compression for NiTi shape memory alloys. Acta Mater 46(12):4325-4338. doi: 10.1016/S13596454(98)00112-8
Luo Z, Chen L, Yang J, Zhang Y, Abdel-Malek K (2005) Compliant mechanism design using multi-objective topology optimization scheme of continuum structures. Struct Multidiscip 0 30:142-154. doi: 10.1007/s00158-004-0512-y

Mabe JH, Gravatt L, Bushnell G, Gutmark E, DiMicco RG, Harris C [2008] Shape memory alloy actuators for deployable rotor blade aerodynamic devices. Proceedings of the 46th AIAA Aerospace Sciences Meeting and Exhibit; Reno, USA. doi: 10.2514/6.2008-1451

Mathew AP, Oksman K, Sain M (2005) Mechanical properties of biodegradable composites from poly lactic acid (PLA) and microcrystalline cellulose (MCC). J Appl Polymer Sci 97(5):2014-2025. doi: 10.1002/ app.21779

Medeiros RR (2011) Projeto, construção e testes de um modelo de asa de perfil variável. São José dos Campos: Instituto Tecnológico de Aeronáutica.

Otsuka K, Wayman CM (1998) Shape memory materials. Cambridge: Cambridge University Press. Chapter 1, Introduction; p. 1-2.

Saggere L, Kota S (1999) Static shape control of smart structures using compliant mechanisms. AIAA J 37(5): 572-578. doi: 10.2514/2.775

Shili L, Wenjie G, Shujun L (2008) Optimal design of compliant trailing edge for shape changing. Chin J Aeronaut 21(2):187-192.doi: 10.1016/S1000-9361(08)60024-2

Sofla AYN, Meguid SA, Tan KT, Yeo WK (2010) Shape morphing of aircraft wing: status and challenges. Mater Des 31(3):1284-1292. doi: 10.1016/j.matdes.2009.09.011

Strelec JK, Lagoudas DC, Khan MA, Yen J (2003) Design and implementation of a shape memory alloy actuated reconfigurable airfoil. J Intell Mater Syst Struct 14[4-5):257-273. doi: 10.1177/104538903034687

Sun L, Huang WM, Ding Z, Zhao Y, Wang CC, Purnawali H, Tang C [2012] Stimulus-responsive shape memory materials: a review. Mater Des 33:577-640. doi: 10.1016/j.matdes.2011.04.065

Wright JR, Cooper JE (2007) Introduction to aircraft aerolasticity and loads. West Sussex: John Wiley \& Sons. Chapter 9, Static aeroelasticity - effect of wing flexibility on control effectiveness; p. 141-151. 